\title{
Apontamentos sobre o uso das TIC nas aulas remotas: um estudo com professores da Educação Básica
}

\author{
Notes on the use of ICT in teaching remote: a study with teachers of Basic \\ Education
}

\author{
Robson Lima de Arruda \\ Mestre em Formação de Professores \\ Universidade Estadual da Paraíba - UEPB. \\ Campina Grande, Paraíba - Brasil. \\ robsonlima13@hotmail.com \\ Robéria Nádia Araújo Nascimento \\ Doutora em Educação \\ Universidade Federal da Paraíba - UFPB. \\ João Pessoa, Paraíba - Brasil. \\ rnadia@terra.com.br
}

\begin{abstract}
Resumo: $\mathrm{O}$ texto apresenta uma pesquisa sobre o ensino remoto na esfera da Educação Básica, motivado pela pandemia do novo coronavírus. Articula dados obtidos entre professores que avaliam a apropriação das tecnologias nessas circunstâncias atípicas da educação, traçando parâmetros que caracterizam a educação presencial e a remota. As contribuições revelam as dificuldades da conjuntura de afastamento físico das instituições escolares e sinalizam a escola enquanto lócus de interação e aprendizagem significativa, sobretudo destacando o papel docente como instrumento mediador dos processos de aprendizagem.
\end{abstract}

Palavras-chave: Ensino Remoto. Educação Básica. TIC na educação.

Abstract: The text presents a research on remote education in the sphere of Basic Education, motivated by the pandemic of the new coronavirus. It articulates data obtained between teachers who assess the appropriation of technologies in these atypical circumstances of education, tracing parameters that characterize classroom and remote education. The contributions reveal the difficulties of the physical distance of school institutions and signal the school as a locus of interaction and meaningful learning, especially highlighting the teaching role as a mediating tool in the learning processes.

Keywords: Remote Education. Basic education. ICT in education.

Cite como

(ABNT NBR 6023:2018)

ARRUDA, Robson Lima de; NASCIMENTO, Robéria Nádia Araújo. Apontamentos sobre o uso das TIC nas aulas remotas: um estudo com professores da educação básica. Dialogia, São Paulo, n. 37, p. 1-17, e18144, jan./abr. 2021. Disponível em:

https://doi.org/10.5585/dialogia.n37.18144

American Psychological Association (APA)

Arruda, R. L. de., \& Nascimento, R. N. A. . (2021, jan./abr.). Apontamentos sobre o uso das TIC nas aulas remotas: um estudo com professores da Educação Básica. Dialogia, São Paulo, 37, p. 1-17, e18144. https://doi.org/10.5585/dialogia.n37.18144. 


\section{Introdução}

O distanciamento social, ocasionado pela pandemia do novo coronavírus, teve implicações diversas nos modos de vida da população, requisitando novas adequações e reajustes a esse novo cenário. As consequências desse acontecimento são de uma complexidade ininteligível, de modo que "qualquer tentativa de aprisionar analiticamente está condenada ao fracasso, dado que a realidade vai ser sempre adiante do que pensamos ou sentimos sobre ela" (SANTOS, 2020, p. 9). Nesse sentido, nossos esforços consistem em verificar os impactos desse cenário para a aprendizagem, apontando encaminhamentos que nos ajudem a pensar a Educação Básica (ou o ensino remoto?) a partir do posicionamento dos professores.

O fechamento de escolas e universidades demandou a adoção de medidas que possibilitassem a continuidade do vínculo entre escola e família, alunos e professores, a fim de proporcionar alternativas de aprendizagem em meio à pandemia da Covid-19. No Brasil, essas deliberações ocorreram à medida que Estados e municípios foram se organizando internamente, de acordo com cada realidade, haja vista a falta de um posicionamento, planejamento e sistematização do Governo Federal para lidar com este cenário pandêmico.

A propósito do uso de plataformas on-line, sabe-se que as tecnologias da informação e da comunicação possibilitam processos de socialização por vias de "uma complexa teia de interações que plasmam a sociabilidade contemporânea e oferecem novas possibilidades de acessos ao saber" (NASCIMENTO; LIMA, 2019, p. 29). Todavia, é preciso ampliar o olhar para além das possibilidades do uso das TIC e adentrar na discussão sobre o acesso e manejo de recursos por professores e alunos para fins pedagógicos no contexto da pandemia.

A presente pesquisa visa dar um passo nessa direção observando o processo das aulas remotas, realizadas por exigência do distanciamento físico. Trata-se de um estudo exploratório, cujo objetivo consiste em possibilitar maior familiaridade do pesquisador com um determinado fenômeno, de modo a aprimorar idéias, modificar ou esclarecer conceitos. É um tipo de estudo com procedimentos sistemáticos e flexíveis que envolvem, por exemplo, levantamento bibliográfico, entrevista com pessoas envolvidas no problema pesquisado e a análise de exemplos para despertar compreensões (GIL, 2002; LAKATOS \& MARCONI, 2003). Para isso, contactamos professores através de uma coleta de dados via plataforma Google Forms. A análise reflete uma abordagem quanti-qualitativa aliada a representações gráficas e trechos de depoimentos fornecidos pelos participantes a fim de ilustrar o contexto empírico.

As discussões sugeridas pretendem colaborar com o debate sobre os impactos da pandemia na prática pedagógica, sinalizando a importância do uso das tecnologias na educação para além 
desse período emergencial, sem perder de vista o papel do professor como essencial ao processo de mediação das aprendizagens. Nesse sentido, problematiza o uso das ferramentas tecnológicas a fim de inspirar outras análises temáticas dessa natureza.

\section{Educação em tempos de pandemia: as simulações da presença}

A educação escolar é fortemente marcada pela interação da presença: o abraço, o olho no olho, os encontros em grupo, as brincadeiras no pátio, a euforia do recreio, bem como o silêncio e concentração na troca de experiências, na leitura compartilhada, enfim, tudo aquilo que transforma a escola em ambiente de socialização e produção de saberes vinculados à presença num mesmo tempo e espaço. Por hora, enquanto dura a pandemia, ainda que algumas das atividades mencionadas possam ser vivenciadas virtualmente, nada consegue substituir o estar juntos, o que torna as atividades remotas experimentações de proximidade com fins didáticos.

No contexto da pandemia, as tecnologias têm, de certo modo, favorecido uma "pedagogia da presença". No entanto, conforme adverte Moronte (2020), elas podem esfriar e "coisificar" as relações tornando-as mais distanciadas, à medida que não são espontâneas e possuem objetivos mais pragmáticos. Para o autor, "quando estamos em uma relação presencial, se torna mais fácil criarmos empatia com o outro, interagirmos de forma a tentar compreender o que se passa com cada colega, suas dificuldades, suas qualidades, seu jeito de ser" (MORONTE, 2020, p.222).

Ao evocarmos a pedagogia da presença, não nos remetemos apenas à dimensão física, afinal, é possível estar presente estando distante e estar ausente estando próximo fisicamente. Nosso enfoque chama atenção para a complexidade da escola enquanto espaço de produção de saberes e de interações cotidianas. Nesse sentido, não nos referimos apenas ao estar dentro da escola, mas àquilo que ocorre a partir dela, visto que a educação não se resume ao que é construído no seu espaço físico, mas também nas relações estabelecidas com o contexto na qual ela está inserida, transformando a presença em convivência e o estar no contexto num estar com ele (FREIRE, 2018).

A pandemia do novo coronavírus produziu o que Giddens (1991) chamou de desencaixe, ou seja, o “'deslocamento 'das relações sociais de contextos locais de interação e sua reestruturação através de extensões indefinidas de tempo-espaço" (GIDDENS, 1991, p.24). Em decorrência disso, a escola se diluiu nos lares dos alunos, gerando a necessidade de reorganizar os modos de interação dentro da família e desta com a escola, bem como a reelaboração, por parte dos professores, de algumas concepções e práticas pedagógicas. 
Enquanto o ensino presencial possibilita que os recursos e estratégias utilizadas sejam ofertados de modo coletivo, democrático e equivalente, o ensino remoto não chega aos alunos numa mesma proporção. Aliás, em alguns casos, sequer os alunos são alcançados, dadas as impossibilidades e limitações existentes, sobretudo nos contextos das famílias mais vulneráveis, o que exige uma discussão no âmbito socioeconômico que extrapola a finalidade deste texto.

Nesse sentido, convém destacar, conforme argumenta Nóvoa (2020), que não se deve abdicar da escola como um espaço público e coletivo, pois a educação presencial possibilita lógicas de comprometimento e cooperação entre alunos e professores que são fundamentais para o desenvolvimento cognitivo.

Concordando com Delors (1998), entendemos que a interação presencial viabiliza a construção de habilidades que extrapolam o campo cognitivo, abrangendo, além das dimensões do conhecer, ser e fazer, o conviver com o outro. Nessa perspectiva, "desenvolver esta atitude de empatia, na escola, é muito útil para os comportamentos sociais ao longo de toda a vida" (DELORS, 1998, p. 98).

Destarte, diante do impedimento temporário das relações presenciais, Nóvoa (2020) defende que escolas e professores se façam presentes na vida de seus alunos. Para ele, é "sobretudo nos momentos mais difíceis [...] que é preciso estarmos presentes. Não podemos abandonar uns aos outros" (NÓVOA, 2020, on-line). No entanto, é preciso pensar a natureza da presença e compreender o que ela objetiva e como se efetivou nesse contexto de atividades remotas.

Em muitas realidades, o ensino remoto esteve condicionado à orientações curriculares burocráticas sob o argumento de que é preciso garantir aprendizagens que, em tese, demandam estruturas de interação mais complexas. Nesse sentido, a humanização dos processos pode ter ocupado lugar secundário, potencializando sentimentos ambivalentes que mesclam aspectos da reinvenção e superação de algumas limitações, mas também de angustia, impotência, culpa, exclusão, entre outros. Nesses termos, Santos (2020) destaca que "a quarentena não só torna mais visíveis, como reforça a injustiça, a discriminação, a exclusão social e o sofrimento imerecido" (SANTOS, 2020, p.21).

\section{Tecnologias digitais e ensino remoto: e agora?}

Estamos vivendo a era da comunicação digital, ou como caracterizou Castells (1999), a era informacional, marcada pela forte presença da internet cuja "rede de comunicação redefine a vida 
ARRUDA, Robson Lima de; NASCIMENTO, Robéria Nádia Araújo. Apontamentos sobre o uso das TIC nas aulas remotas: um estudo com professores da educação básica

e altera profundamente a forma de adquirir conhecimento e de nos relacionarmos" (NASCIMENTO; LIMA, 2019, p.29).

A urgência por estratégias de ensino remoto demandou dos profissionais da educação, principalmente os professores, a apropriação e uso das ferramentas tecnológicas para manter o vínculo com os alunos e oferecer possibilidades de aprendizagem. No entanto, a escassez ou inexistência desses recursos em muitos lares brasileiros não pode passar despercebida, considerando que essa exclusão fere o princípio constitucional da garantia de acesso à educação para todos.

A respeito das aulas remotas, Soares (2020) comenta que:

\begin{abstract}
A sua implementação de modo aligeirado esbarra na falta de acesso à internet de grande parcela dos estudantes e inclusive de uma significativa parte do corpo docente. A isso soma-se o desconhecimento de um amplo setor do professorado no manejo de tecnologias para elaborar uma aula minimamente "interativa". Assim, onde ainda se consegue realizar as ditas atividades virtuais, elas acabam, muitas vezes, por se constituírem em um mero aprofundamento das metodologias tradicionais (exercícios, correções, aulas expositivas) e não em um aproveitamento da tecnologia para desenvolver técnicas mais atrativas e estimulantes de aprendizagem (SOARES, 2020, p. 8).
\end{abstract}

Além do escasso ou inexistente acesso às tecnologias da informação e comunicação e à internet, parte das dificuldades nas aulas remotas, durante a pandemia da Covid-19, é um reflexo da falta de formação e da ausência desses recursos no cotidiano das aulas presenciais, resultando em uma mudança que, para muitos professores, foi ameaçadora. Sobre isso, Mercado (1999) assevera que a entrada das tecnologias nas aulas esbarra na resistência à mudança, na falta de domínio das novas tecnologias, nos custos excessivos, na falta de identificação dos objetivos, ênfase no meio e não na mensagem, entre outros fatores que merecem observação.

Nesse sentido, é preciso refletir sobre o uso das tecnologias na educação, a fim de ultrapassar a concepção de mero domínio técnico de ferramentas, aplicativos, softwares e demais recursos, pois como argumenta Mercado (1999):

As tecnologias, por si só, não são veículos para aquisição de conhecimento, capacidades e atitudes, mas precisam estar integradas em ambientes de ensino-aprendizagem, situações que permitam ao aluno os processos de aprendizagem necessários para atingir os objetivos educacionais desejados (MERCADO, 1999, p. 60).

Além daqueles que não dispõem dos recursos tecnológicos necessários para as aulas remotas, um aspecto da dificuldade na realização das atividades remotas pode estar relacionada ao uso esporádico e, muitas vezes, equivocado destas ferramentas durante as aulas presenciais. Em muitos casos, eles são utilizados apenas como instrumento para transmissão das atividades trabalhadas de forma expositiva, ou no envio de exercícios para serem respondidos nos cadernos 
e livros. Com isso, reiteramos que pensar em práticas de ensino remoto exige "refletir sobre o conceito mais amplo, que é o uso das (novas) tecnologias de informação e comunicação" (BELLONI, 2002, p.122). Cumpre pensar que "a introdução das tecnologias não pode ser considerada apenas como uma mudança tecnológica, não é simplesmente a substituição do quadro negro ou o livro pelas novas tecnologias" (MERCADO, 1999, p.31). Desse modo, os ambientes online devem ser definidos como espaços de sociabilidade, organização, interação, comunicação, informação e conhecimento (NASCIMENTO; LIMA, 2019).

Soares (2020) argumenta que as aulas remotas deram à educação bancária ${ }^{1}$ um ar de modernidade pelo fato de os conteúdos terem sido depositados pelos "professores hologramas", tornando o ensino ainda mais enfraquecido e alienante.

\footnotetext{
O que se pode observar é a "modernidade" tecnológica servindo para reforçar o que há de mais arcaico pedagogicamente. É a modernização conservadora da educação, o intento de inovar para manter as estruturas sociais tal qual estão. O educar vira sinônimo de conteúdo e aula expositiva, os projetos, as peças de teatro e demais processos educativos vão deixando de fazer parte das metodologias de aprendizagem, pois são impossíveis de se desenvolver nessa lógica virtual (SOARES, 2020, p. 8-9).
}

Assim, ainda que o ensino remoto seja uma condição temporária, devemos nos valer desse contexto para ressignificar algumas concepções pedagógicas e produzir, junto aos professores, novos entendimentos que embasarão, ainda mais, a defesa da escola pública, gratuita, para todos. Outrossim, estas discussões se fazem necessárias não apenas no âmbito teórico, mas, principalmente no campo das práticas, nos interiores das escolas, em conjunto com a sociedade e toda comunidade educativa.

\section{Percurso metodológico}

A pesquisa em tela configura-se como um estudo exploratório (GIL, 2002; LAKATOS \& MARCONI, 2003) e desenvolveu-se na perspectiva da abordagem qualitativa que tem por objetivo a compreensão das aparências dos fenômenos, bem como das causas de sua existência "procurando explicar sua origem, suas relações, suas mudanças e se esforça por intuir as conseqüências que terão para a vida humana" (TRIVIÑOS, 1987, p. 129, grifos do autor). Conforme Minayo (1994), esse tipo de pesquisa busca trabalhar com sentidos, motivos, aspirações, valores e atitudes correspondentes às relações e fenômenos pesquisados. Nesse sentido, o presente estudo tem por

\footnotetext{
1 Segundo Paulo Freire, a educação bancária é "puro treino, é pura transferência de conteúdo, é quase adestramento, é puro exercício de adaptação ao mundo" (FREIRE, 2000, p.101). In: Pedagogia da indignação: cartas pedagógicas e outros escritos. São Paulo: Editora UNESP, 2000.
} 
objetivo analisar a percepção dos professores da educação básica sobre as aulas remotas e discutir aspectos do uso das tecnologias no ensino remoto emergencial, durante a pandemia da Covid-19.

Os dados da pesquisa foram obtidos através de um formulário disponibilizado na plataforma Google Forms, entre os dias 23 de junho a 08 de julho de 2020. As informações fornecidas pelos docentes são analisadas quanti-qualitativamente por meio de gráficos e trechos de depoimentos dispostos ao longo do texto. Ao optarmos pela mescla quanti-quali, nos apoiamos em Triviños (1987) quando argumenta que "toda pesquisa pode ser, ao mesmo tempo, quantitativa e qualitativa” (TRIVIÑOS, 1987, p.118). Nessa perspectiva, não há oposição entre os dois tipos de modo que a combinação entre ambas pode enriquecer a compreensão da pesquisa (GATTI, 2004) e colaborar com o pesquisador no alcance dos objetivos e extração de significados importantes da mensagem (LAVILLE; DIONNE, 1999).

Ressaltamos que não é nossa intenção apresentar uma amostra representativa do grupo estudado e que a ampla divulgação do formulário teve por objetivo o alcance de contextos, experiências e percepções diversificadas. Destacamos, ainda, que não pretendemos esgotar todas as possibilidades de análise sobre o tema, mas contribuir com o debate sobre a educação em tempos de pandemia, a partir de experiências concretas que sirvam para compreender o contexto vivido e aponte novos caminhos para análise.

\section{Discussão dos resultados}

A pesquisa agregou a participação de 118 professores da Educação Básica, oriundos das regiões Nordeste (62\%), Sul (28\%), Sudeste (6\%), Norte (2\%) e Centro-Oeste (2\%). Inicialmente, introduziremos alguns dados referentes aos participantes da pesquisa, a fim de situá-los no contexto da análise. A apresentação de trechos dos depoimentos dos professores será representada da letra $\mathrm{P}$ (professor/professora), seguida de um número correspondente à ordem de respostas no formulário.

No aspecto sociodemográfico dos participantes da pesquisa, $82,2 \%$ são do sexo feminino e 17,8\% do sexo masculino. A maior parte deles leciona em apenas uma escola (71,2\%). O gráfico 1 mostra o campo de atuação quanto à localização das escolas e tipo de rede de ensino. 


\section{Dialogia}

ARRUDA, Robson Lima de; NASCIMENTO, Robéria Nádia Araújo. Apontamentos sobre o uso das TIC nas aulas remotas: um estudo com professores da educação básica

Gráfico 1 - Localização e tipo de rede de ensino dos professores participantes da pesquisa

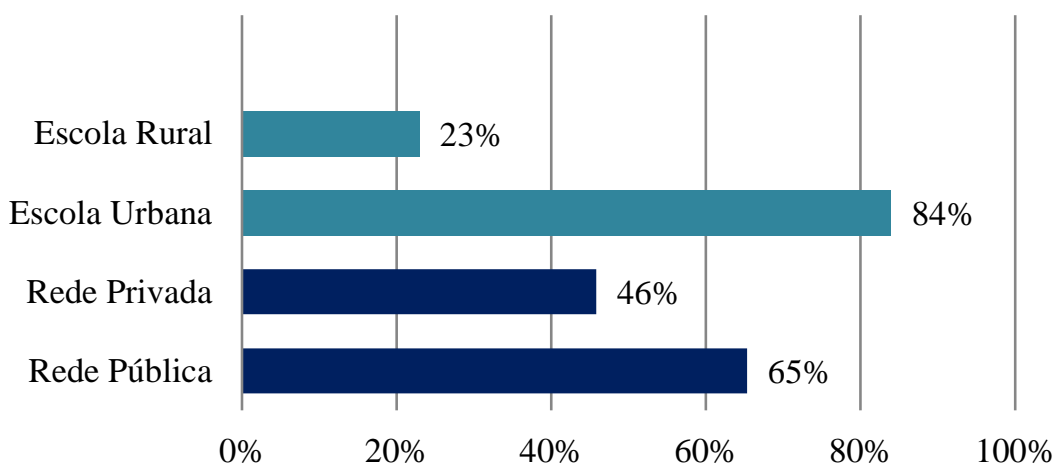

Fonte: Elaborado pelos autores.

Relativo à formação profissional/acadêmica, verificou-se que $62,7 \%$ possui especialização, seguido da graduação (22,9\%), Mestrado (8,4\%), Doutorado (3,4\%) e Nível Médio (2,5\%). O gráfico 2 ilustra o tempo de docência dos participantes.

Gráfico 2 - Tempo de atuação docente

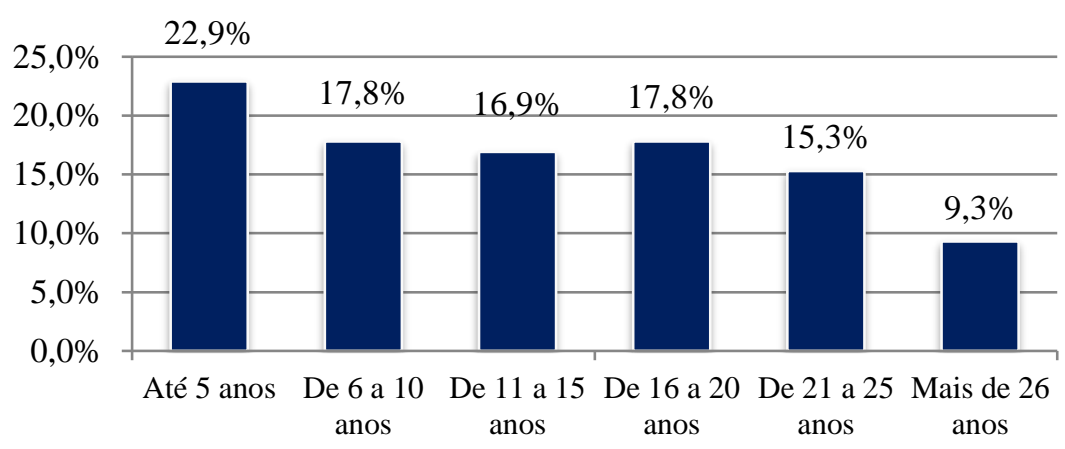

Fonte: Elaborado pelos autores.

Os dados acerca da formação inicial e o tempo de docência dos professores nos interessam, dentro da análise realizada, considerando que tais fatores têm implicações consideráveis, tanto nas concepções pedagógicas, como nas práticas docentes produzidas no contexto da pandemia.

Ao perguntarmos se os professores concordam com a realização das aulas remotas, obtivemos o seguinte resultado: $50,8 \%$ concordam, 44,1\% concordam com ressalvas e 5,1\% não concordam. A escala abaixo representa os níveis de aceitação dos professores em relação à questão. A escala é progressiva de modo que o número 1 significa aprovação mínima e o número10 significa aprovação máxima. 
Gráfico 3 - Escala de aprovação da realização das aulas remotas

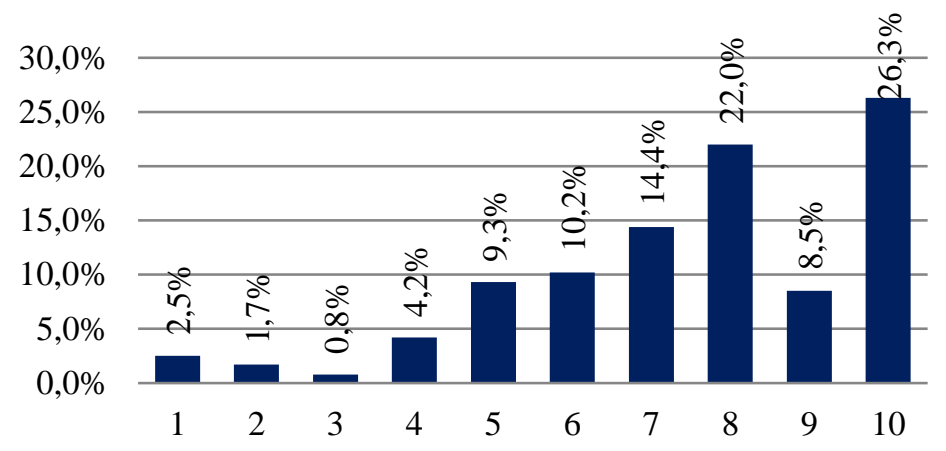

Fonte: Elaborado pelos autores.

Conforme notamos, a maioria dos professores participantes da pesquisa concorda com as aulas remotas, porém, boa parte dos depoimentos expressam sentimentos e percepções ambivalentes. Destacamos alguns depoimentos para ilustrar o que pensam esses docentes:

Como professora, as aulas remotas, para mim, foi um grande desafio. Não estávamos
preparados para passarmos por algo novo, que não estava dentro do nosso cotidiano.
(P81).
A melhor forma -em minha opinião- é respeitar os alunos como indivíduos e apenas dar
continuidade ao processo de ensino-aprendizagem, sem forçar barras e limites. (P90).
Estressante. Alunos descompromissados. Mera formalidade no cumprimento de
calendário e programa. (P102)
Todos nós professores fomos pegos de surpresa nesta situação durante a Pandemia. As
aulas on-line não são suficientes e nem eficientes para ensinar os alunos. [...] A qualidade
da interação professor aluno retrocedeu para aulas 90\% expositivas. [...] Os pais estão
ainda perdidos e atolados com suas atividades de trabalho e agora tem que virar professor
sem ter a experiência para tal função. Estamos brincando de ensinar!!!! (P114).

No contexto da pandemia da Covid-19, o ensino remoto demandou a "transformação" de casas em escolas e em "studios" de gravação, no caso dos alunos e professores, respectivamente. Nesses espaços compartilhados com outros parentes, profissionais e alunos experimentaram situações de cooperação em meio às adversidades decorrentes do confinamento.

De acordo com a nossa pesquisa, 47,5\%dos professores apresentaram pouca dificuldade na realização do homeoffice. ${ }^{2}$ Os que apresentaram muita dificuldade representam $38,1 \%$ e os que afirmaram não ter tido nenhum problema para trabalhar em casa somaram 14,4\%. Cumpre ressaltar que cada profissional possui uma maneira específica de lidar com as tecnologias, ressaltadas as limitações e possibilidades de cada um frente às TIC (MERCADO, 1999).

O trabalho na própria residência demanda maior organização com horários e rotinas, pois ali são compartilhadas outras atividades como os afazeres domésticos e cuidado com filhos, por

\footnotetext{
${ }^{2} \mathrm{O}$ home office é uma prática de flexibilização do trabalho com abrangência de três principais dimensões: o local (geralmente em casa); o tempo (não há horário fixo) e a comunicação/produção (via internet).
} 
exemplo. Além disso, o atendimento remoto aos alunos nem sempre ocorreu de forma síncrona, exigindo flexibilidade e disponibilidade para atendê-los em horários diferentes do estipulado. $\mathrm{O}$ gráfico 4 mostra a organização de horários disponibilizados pelos professores para as aulas remotas.

Gráfico 4 - Horário de atendimento remoto aos alunos

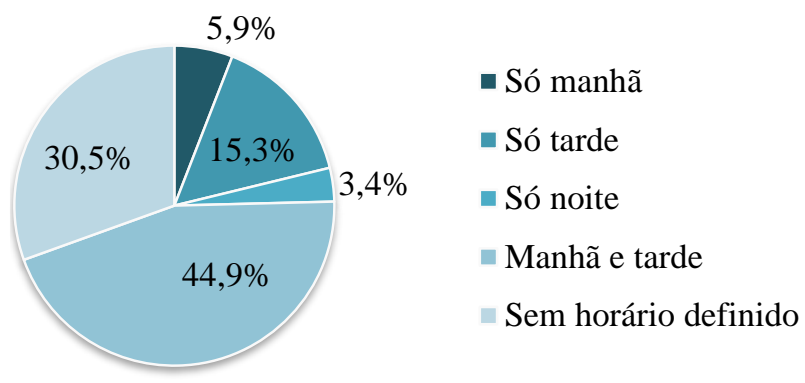

Fonte: Elaborado pelos autores.

No aspecto da organização de horários de atendimento remoto, a pesquisa mostrou que a maioria dos docentes estendeu o trabalho remoto aos sábados e domingos. Segundo os dados obtidos, $84,6 \%$ dos professores afirmaram fazer atendimento remoto aos alunos nos fins de semana. Desses, 43,6\% afirmaram que o fazem às vezes, $28,2 \%$ disseram que sempre, $12,8 \%$ disseram que pouco. Outros 15,4\% afirmaram que nunca respondiam ou orientavam alunos nos fins de semana. Alguns relatos ilustram como esses docentes extrapolaram os dias e horários letivos para conseguir atender seus alunos:

\footnotetext{
A maior dificuldade é para chegar aos alunos que não tem acesso à internet, em decorrência desse fator termino ficando disponível quase que o dia e a noite e nos finais de semana também. (P22).

Nós como professores, estamos tendo o trabalho triplicado durante a pandemia, passamos a maior parte do tempo preparando material e atendendo alunas fora do nosso horário, sem contar que não recebemos nada mais por isso. [...] A situação é complicada (P106).

São poucos os que têm condições de dispor de dispositivos apropriados para receber e enviar as atividades proposta! Os que têm, geralmente, dividem com os irmãos, que também precisam ver as explicações pra fazer as atividades, e com os pais, que tem que levar para o trabalho, o único meio de comunicação da família. Por consequência, sobrando somente o horário da noite, para todos "assistirem" as aulas e fazerem as atividades, dando a devolutiva aos professores, somente no dia seguinte (muitas vezes não mandam) ou em horários que extrapolam o horário das "aulas". (109)
}

Em relação às tecnologias, entendemos que elas são parte de nossa sociedade e, portanto, quando falarmos nesse assunto, não estamos nos referimos a uma novidade. Dados do Cetic-br ${ }^{3}$ comprovam tal assertiva apontando que, em 2019, 99\% dos professores das escolas rurais já haviam

\footnotetext{
${ }^{3}$ Disponível em: https://cetic.br/pt/pesquisa/educacao/indicadores/ Acesso em: 13 de junho de 2020.
} 
acessado internet e que $99 \%$ dos professores das escolas urbanas possuíam acesso à internet em casa (CETIC.BR, 2019). Contudo, o fato de os professores utilizarem aparelhos tecnológicos com acesso à internet não significa que se sintam seguros e preparados para utilizá-los em suas atividades pedagógicas, convencionando o que Soares (2020) chamou de aprofundamento de metodologias tradicionais, mesmo num cenário de utilização das TIC.

Em nossa pesquisa, 48,3\% dos professores disseram que usavam a internet em suas aulas (diária ou semanalmente), antes da pandemia. Os demais apresentaram índices considerados de baixo uso (quinzenal, mensal, bimestral) ou até mesmo inexistente, totalizando 51,7\%, conforme ilustra o gráfico 5 :

Gráfico 5 - Frequência do uso da internet em atividades pedagógicas, antes da pandemia do novo Coronavírus

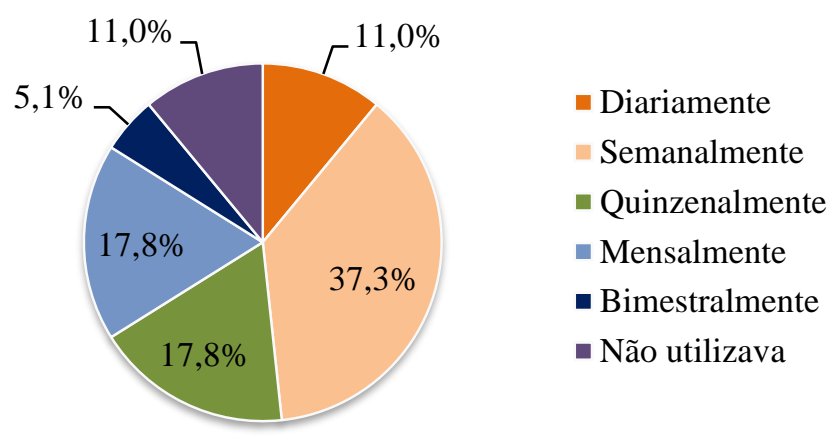

Fonte: Elaborado pelos autores.

Ao questionarmos como os professores definem as próprias habilidades com o manuseio de aplicativos para gravação e edição de vídeo aulas, os dados revelaram que 48,3\% afirmaram sentir dificuldades (entre péssimo e regular) e que 15,3\% disseram ter facilidade (entre excelente e ótimo), conforme mostra o gráfico 6:

Gráfico 6 - Habilidades dos professores no manuseio de aplicativos de gravação e edição de vídeos para aulas remotas

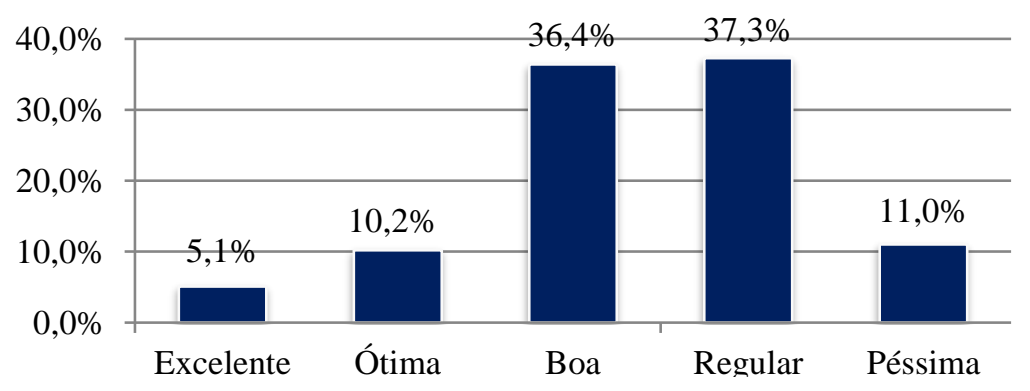

Fonte: Elaborado pelos autores. 


\section{Dialogia}

ARRUDA, Robson Lima de; NASCIMENTO, Robéria Nádia Araújo. Apontamentos sobre o uso das TIC nas aulas remotas: um estudo com professores da educação básica

No tocante à preparação, postagem e utilização das aulas on-line, cumpre destacar o uso do aparelho celular como principal ferramenta desse tipo de trabalho. Todavia, o acesso à internet apenas pelo celular configura limites e impossibilidades diversas tanto do ponto de vista da capacidade técnica e tecnológica do aparelho quanto da habilidades de seus usuários.

O gráfico 7 mostra o tipo de aparelho que os professores utilizaram para acessar internet e mediar as aulas remotas, e o gráfico 8 apresenta os recursos utilizados pelos docentes para interagir, enviar e/ou receber dados durante as aulas remotas.

Gráfico 7 - Tipo de aparelho utilizado pelos professores para mediar as

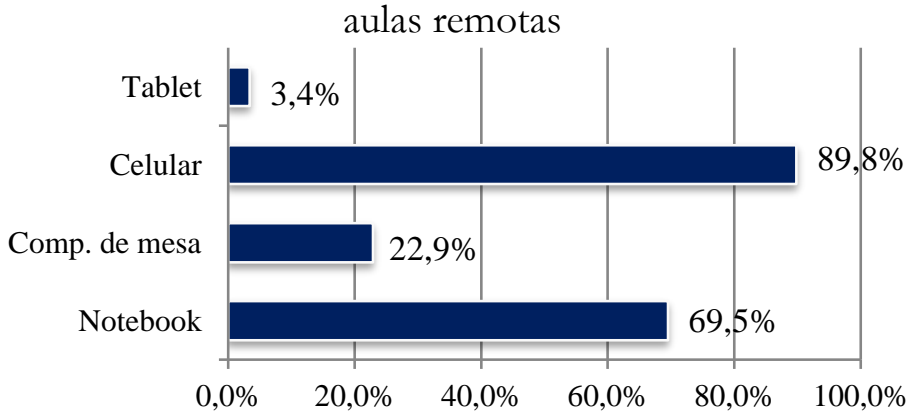

Fonte: Elaborado pelos autores.

Gráfico 8 - Recursos utilizados para envio e recebimento de dados e interação nas aulas

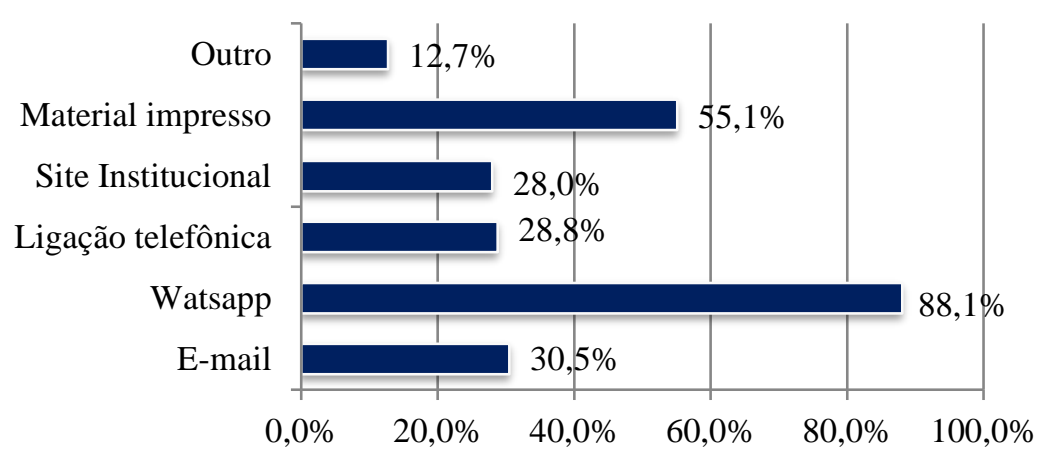

Fonte: Elaborado pelos autores.

Os dados expostos nos gráficos 7 e 8 reforçam o celular como principal recurso tecnológico utilizado nas aulas remotas e, da mesma forma, podemos supor que é através dele que os professores acessam o aplicativo Whats $A$ ph, que lidera a lista de recursos manobrados para envio e recebimento de dados. Chama-nos atenção, também, o fato de os materiais impressos ocuparem uma posição elevada no conjunto dos instrumentos utilizados para envio e recebimento de conteúdos. Ocorre que este é um processo que exige uma boa logística e cuidados com a 
higienização, exatamente por se tratar de um recurso que não pode ser enviado via internet, salvo em raros casos em que os alunos tenham impressora em casa. Entretanto, as atividades impressas foram utilizadas em contextos e situações onde o acesso à internet não existe ou é precário:

Minha realidade em uma escola do campo no interior é muito complicada. A maioria dos
alunos não possui acesso à internet e quando possuem é de péssima qualidade. Estamos
entregando atividades impressas e usamos o livro didático, porém muitos alunos não
fazem ou não conseguem fazer sozinhos. (P43).
É tudo muito novo e nos deparamos com muitas dificuldades, principalmente a
dificuldade das famílias de ter acesso à Internet e aos aparelhos eletrônicos. É algo que
não é acessível a todos. (P49).
Eu leciono em uma comunidade rural e nesse tempo de Pandemia o trabalho ficou difícil,
por que $50 \%$ dos alunos não tem acesso à internet. Eu preparo atividades impressas para
todos os alunos e os que têm acesso à internet ou mesmo telefone celular, eu ligo ou faço
chamada de vídeo para acompanhar nas atividades e os que não têm acesso a internet, as
atividades são devolvidas para o professor apenas quando iniciar as aulas presenciais.
(P99).

Com base nos depoimentos acima, entendemos que o envio de atividades impressas, decorrentes da falta de internet, representa uma maior precarização do atendimento remoto aos alunos, tendo em vista que nem sempre há alguém em casa para ajudá-los ou que a forma como essas atividades foram disponibilizadas (semanalmente ou quinzenalmente, por exemplo) pode gerar um entendimento de que as aulas não passam de mero cumprimento de tarefas escolares, limitadas a orientações por ligações telefônicas ou até mesmo sem a mediação dos professores.

Quando se trata da exploração de conteúdos e temáticas, as atividades impressas prevalecem como um dos recursos ou ferramentas mais utilizadas nas aulas remotas ficando atrás apenas dos vídeos $(91,5 \%)$, áudios $(75,4 \%)$ e imagens $(75,4 \%)$, conforme mostra o gráfico 9:

Gráfico 9 - Recursos ou ferramentas utilizadas para explorar conteúdos e temáticas nas aulas remotas

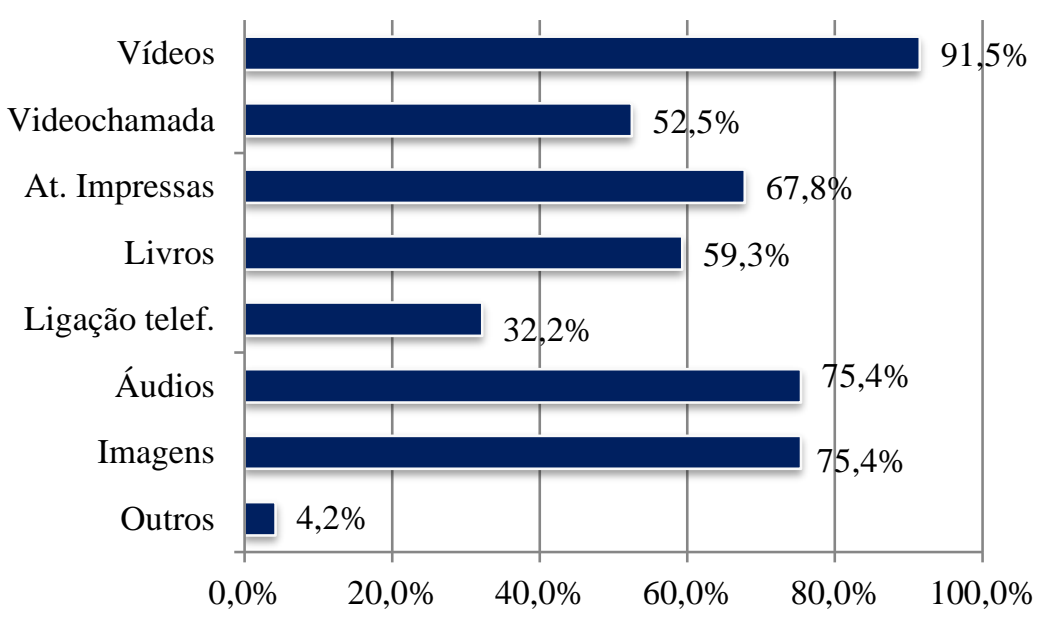

Fonte: Elaborado pelos autores. 
Um aspecto talvez pouco considerado no contexto das aulas remotas diz respeito aos registros e arquivamentos de dados produzidos durante as aulas remotas como áudios, vídeos, imagens, etc. Com as atividades concentradas principalmente em aparelhos celulares e computadores, por exemplo, pode surgir a necessidade de revisar, comprovar, corrigir, avaliar e apresentar informações sobre as aulas. Urge daí, a necessidade de registrar e/ou arquivar o andamento das aulas. O gráfico 10 ilustra como os professores participantes da pesquisa se organizaram nesse sentido:

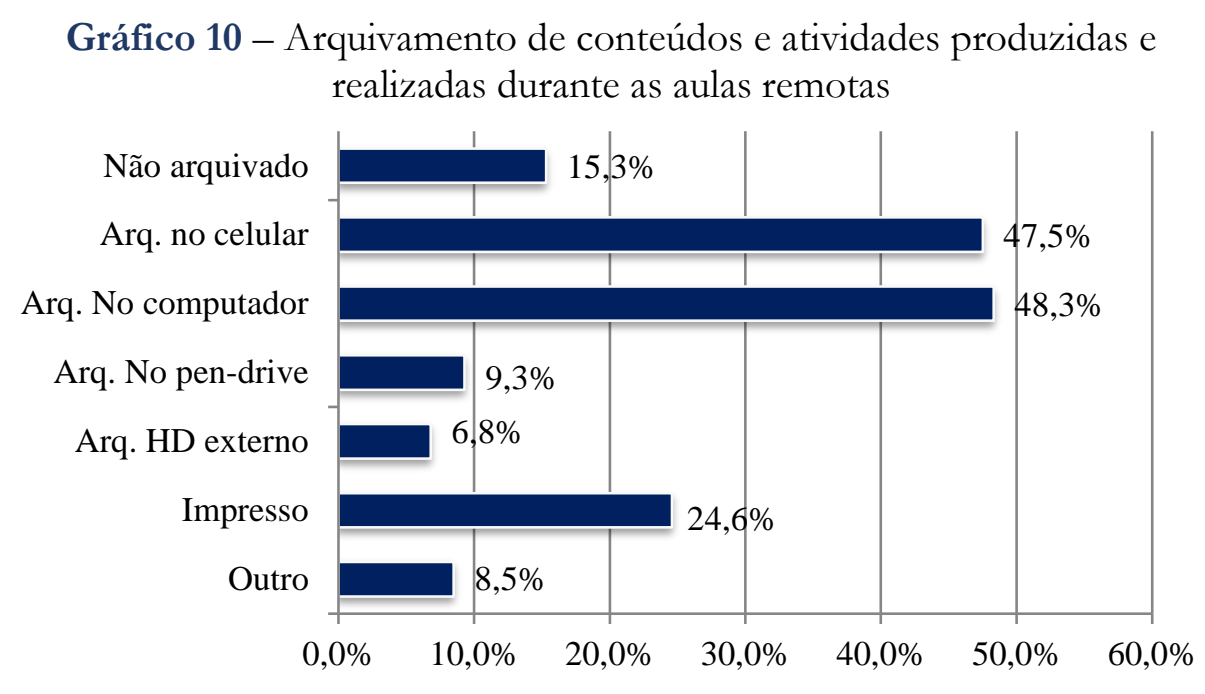

Fonte: Elaborado pelos autores.

Geralmente, o diário e o caderno de planejamento são os instrumentos mais utilizados para os registros das aulas. Durante o ensino remoto, o volume de recebimento e envio de dados e informações se tornou muito superior ao do ensino presencial. Arquivar esses dados requer uma boa memória nos aparelhos ou o uso de suportes de memória externa como pen-drives e HD, por exemplo.

Conforme notamos no gráfico 10, os recursos de memória externa foram utilizados por poucos professores, prevalecendo a memória do próprio aparelho utilizado nas aulas (celular e computador), seguido das impressões $(24,6 \%)$ e do não arquivamento (15,3\%). Ainda, foram citados os canais na plataforma Youtube, One drive e o Google drive como alternativas de registro e arquivamento de dados produzidos nas aulas remotas.

Por fim, destacamos o acesso à internet, aspecto necessário e determinante na elaboração e mediação das aulas remotas. Os gráficos 11 mostra como os professores definem a qualidade da internet utilizada nas aulas remotas e o gráfico 12 aponta o tipo de internet utilizada por eles. 
Gráfico 11 - Opinião dos professores sobre a qualidade da internet utilizada nas aulas remotas

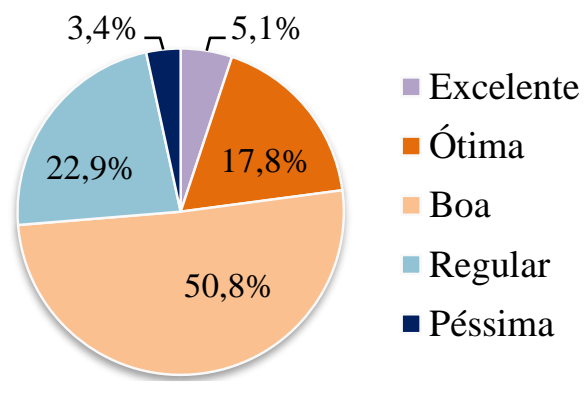

Fonte: Elaborado pelos autores.

Gráfico 12 - Tipo de internet utilizada pelos professores nas aulas remotas

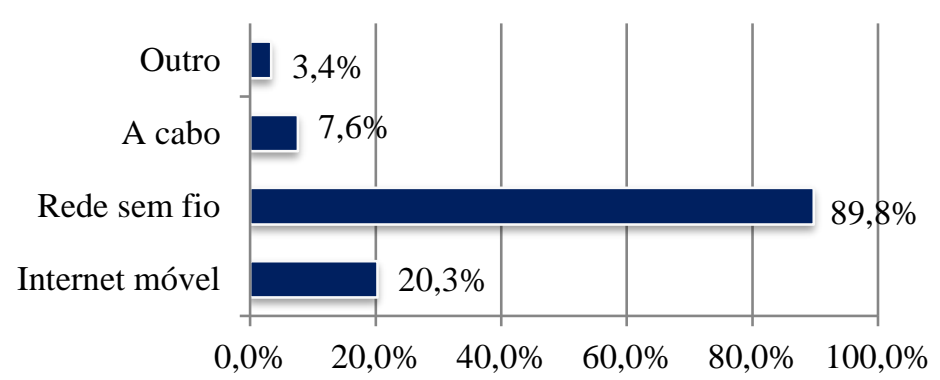

Fonte: Elaborado pelos autores.

Conforme constatamos, a rede sem fio foi a mais utilizada pelos docentes $(89,8 \%)$. Pouco mais da metade deles $(50,8 \%)$, afirmaram que a qualidade da conexão utilizada era boa. Outros $26,3 \%$ considerou internet ruim ou péssima, enquanto 22,9\% afirmou que sua internet era ótima ou excelente. Dessa forma, depreende-se que as aulas remotas on-line da maioria dos professores não devem ter sido prejudicadas considerando que possuíam internet de boa qualidade. No entanto, a precariedade ou falta de acesso à internet, mesmo de uma pequena parte dos professores, é um aspecto que não pode ser negligenciado, afinal, essas situações colaboram para agravar a desigualdade e a exclusão social, digital e educacional.

\section{À guisa de conclusão}

Enquanto espaço legítimo de interações e mediações educativas, a escola viu-se deserta por causa da pandemia da Covid-19. A presença que se dava nesses espaços coletivos dissolveu-se na complexidade de cada casa, requisitando outro tipo de presença: a virtual. Até então, nunca havíamos experimentado um ensino mediado pelas tecnologias tal como vivenciamos no 
distanciamento físico provocado pela pandemia da Covid-19. Com isso, emergiram novas formas de estar presente e novos modos de produzir as interações escolares.

Para maior parte da população, as TIC fazem parte de sua realidade, porém, ainda muito associadas às interações sociais em redes, aplicativos de mensagens, sites e afins. Nesse sentido, o uso das tecnologias como ferramenta de aprendizagem formal é inconsistente. Além disso, essas ferramentas têm sido utilizadas como suporte para reprodução de metodologias consideradas tradicionais e ultrapassadas. Dentre os fatores que colaboram para tal quadro, evidenciam-se a falta de formação e a escassez desses recursos no âmbito escolar e individual.

A presença pedagógica, durante a pandemia, requisitou não apenas o envio e recebimento de informações e conteúdos curriculares, mas também salientou aspectos da sociabilidade, comunicação, interação e conhecimento. Como pudemos constatar, as aulas remotas foram utilizadas com o apoio e engajamento dos professores, ainda que isto tenha exigido demasiados esforços tanto no aspecto profissional quanto pessoal.

A partir das narrativas e apontamentos dos profissionais, vimos seus lares se transformarem em studios e seus horários de "expediente" serem extrapolados pela flexibilização do atendimento aos alunos, incluindo os fins de semana. Do mesmo modo, constatamos que o uso da internet em atividades pedagógicas, antes da pandemia, não era uma prática comum à maioria dos docentes e que, por isso, para muitos professores, o trabalho foi complexo e difícil.

No âmbito das tecnologias como ferramentas pedagógicas, o que a pandemia irá provocar posteriormente na prática dos professores ainda é incerto. Todavia, é salutar que as práticas docentes não retrocedam a limitar-se aos livros, quadros, cadernos e atividades impressas. Com isso, abrem-se possibilidades para novos estudos e pesquisas sobre os desafios e práticas de ensinoaprendizagem mediadas pelas TIC no pós-pandemia. Desse modo, diferentemente da condição imposta pela pandemia, espera-se que novas práticas mediadas com o apoio das tecnologias sejam vivenciadas na escola: espaço legítimo de interação, socialização e desenvolvimento da aprendizagem formal.

\section{Referências}

BELLONI, M. L. Ensaio sobre a educação à distância no Brasil. Educação \& Sociedade, ano XXIII, n. 78, p.117-142, abril/2002.

CASTELLS, Manuel. A sociedade em rede: A era da informação: economia, sociedade e cultura. São Paulo: Paz e terra, 1999.

DELORS, Jacques. Educação: um tesouro a descobrir. Relatório para a UNESCO da Comissão Internacional sobre Educação para o século XXI. São Paulo: Cortez, 1998. 
FREIRE, Paulo. Pedagogia da autonomia: saberes necessários à prática educativa. São Paulo: Paz e Terra, 2018.

GATTI, B. A. "Estudos quantitativos em educação". Educação e Pesquisa, São Paulo, v.30, n.1, p. 11-31. jan./abr. 2004.

GIDDENS, Anthony. As consequências da modernidade. São Paulo: Editora Unesp, 1991.

GIL, Antônio Carlos. Como elaborar projetos de pesquisa. 4.ed. São Paulo: Atlas, 2002.

LAVILLE, Christian; DIONNE, Jean. A construção do Saber. Manual de metodologia de pesquisa em ciências humanas. Porto Alegre. Editora Artmed. Belo Horizonte: Editora UFMG,1999.

LAKATOS, Eva Maria. MARCONI, Marina de Andrade. Fundamentos da Metodologia Científica. 5.ed. São Paulo: Atlas, 2003.

MINAYO, M. C. S. (org.). Pesquisa social: teoria, método e criatividade. Petrópolis, RJ: Vozes, 1994.

MERCADO, Luiz Paulo Leopoldo. Formação continuada de professores e novas tecnologias. Maceió: EDUFAL, 1999.

MORONTE, E. A. A pandemia do novo Coronavírus e o impacto na saúde mental dos trabalhadores e trabalhadoras. In: AUGUSTO, Cristiane Brandão; SANTOS, Rogério Dultra. Pandemias e pandemônios no Brasil. 1.ed. São Paulo: TirantloBlanch, 2020. p.219-228.

NASCIMENTO, Robéria Nádia A.; LIMA, Veronica de Oliveira. Dimensões entrelaçadas do afeto e do saber: a educação de um novo tempo. In: LIMA, V. A.; NASCIMENTO, R. N. A.; ESCOLA, J. J. J. (Orgs). Conhecimento, sociabilidade e humanidade. Campina Grande: EDUEPB, 2019.

NÓvOA, A. Conversa com António Nóvoa. Porto Alegre, 06 abr. 2020. Facebook: Sindicato dos Professores de Novo Hamburgo, 2020. Disponível em:

$<$ https://www.facebook.com/sindprofnh/videos/631629681020563/>. Acesso em 19 de junho de 2020.

SANTOS, B. de S. A Cruel Pedagogia do Vírus. Coimbra: Almedina, 2020.

SOARES, S. B. V. Coronavírus e a modernização conservadora da educação. In: SOARES, S. B. V., et al. Coronavírus, educação e luta de classes no Brasil. Editora Terra Sem Amos: Brasil, 2020. p.5-14.

TIC educação 2019. Comitê Gestor da Internet no Brasil. Disponível em: $<$ https://cetic.br/pt/pesquisa/educacao/ indicadores/>. Acesso em: 20 de julho de 2020.

TRIVIÑOS, A. N. S. Introdução à pesquisa em ciências sociais: a pesquisa qualitativa em educação. São Paulo: Atlas, 1987. 